\title{
Characterization of linoleic acid (C18:2) concentration in commercial corn silage and grain hybrids
}

\author{
M. Baldin, ${ }^{* 1}$ Y. Ying, ${ }^{* 2}$ Y. Fan, ${ }^{*} \dagger^{3}$ G. Roth, $\ddagger$ D. P. Casper, $\S$ and K. J. Harvatine ${ }^{* 4}$ \\ *Department of Animal Science, Penn State University, University Park 16802 \\ †State Key Laboratory of Animal Nutrition, College of Animal Science and Technology, China Agricultural University, Beijing, China 100193 \\ ‡Department of Plant Sciences, Penn State University, University Park 16802 \\ §Furst-McNess Company, 120 E Clark St, Freeport, IL 61032
}

\begin{abstract}
Corn silage and high-moisture corn grain are commonly recognized as risk factors for biohydrogenationinduced milk fat depression and may be due to the high concentration of linoleic acid (C18:2) in corn. Corn silage and corn grain have a low concentration of fatty acids (FA), but due to their high inclusion rate in diets they contribute substantially to unsaturated FA intake. The first objective of this study was to characterize the contribution of individual plant parts to total FA in whole-plant chopped corn. The second objective was to characterize the variation in FA profile in commercial silage and grain hybrids and evaluate the relationship between FA profile and other nutrients. To determine the location of FA in the corn plant, 4 stalks from 4 different commercial hybrids were separated into stalk, husk and shank, leaves, cob, and kernels. On a dry matter basis, $80.5 \%$ of total FA were in the kernels, $11.8 \%$ in the leaves, $5.1 \%$ in the stalk, $1.7 \%$ in the cob, and $1.0 \%$ in the husk and shank. More than $96 \%$ of the oleic acid (C18:1) and $92.5 \%$ of the $\mathrm{C} 18: 2$ was in the kernels, whereas $71.0 \%$ of the linolenic acid (C18:3) was in the leaves. Next, the FA composition of fresh whole-plant chopped corn from 124 silage hybrids and grain from 72 grain hybrids was determined over 2 yr from test plots in Pennsylvania. Last, to extend the characterization, FA composition of whole-plant corn silage from 45 hybrids grown in test plots in South Dakota were characterized. In the fresh whole-plant chopped corn from PA test plots, C18:2 as a percentage of total FA averaged from $48.7 \%$ in 2013 (percentiles:
\end{abstract}

\footnotetext{
Received April 1, 2017.

Accepted August 4, 2017

${ }^{1}$ Current address: Provimi North America, 10 Nutrition Way, Brookville, OH 45309.

${ }^{2}$ Current address: Department of Medicine, Penn Center for Pulmonary Biology, Penn Cardiovascular Institute, University of Pennsylvania, Philadelphia, PA 19104.

${ }^{3}$ Current address: No. 16 Building of No. 5 of Jiangtai Road, Chaoyang District, Beijing, China 100016.

${ }^{4}$ Corresponding author: kjh182@psu.edu
}

10 th $=45.2$, 90th $=52.2$ ) and $48.0 \%$ in 2014 (percentiles: 10 th $=44.1,90 \mathrm{th}=49.4)$. Concentration of C18:2 in corn grain averaged $57.5 \%$ in the 2013 (percentiles: 10 th $=53.4,90$ th $=60.8)$ and $56.1 \%$ in 2014 (percentiles: 10th $=53.5,90$ th $=59.4$ ). In the corn silage from South Dakota, the concentration of C18:2 as percentage of total FA averaged $45.4 \%$ (percentiles: 10 th $=39.4,90$ th $=50.2)$ and C18:2 concentration as a percent of dry matter averaged 1.1\% (percentiles: 10th $=0.76,90 \mathrm{th}=1.41)$. An increase in the concentration of $\mathrm{C} 18: 2$ was associated with a decrease in C18:3 in fresh whole-plant chopped corn and with a decrease in C18:1 in corn grain. Total FA and C18:2 (as a percentage of dry matter) were positively correlated with starch and negatively correlated with neutral detergent fiber in both fresh whole-plant chopped corn and corn silage samples, whereas no correlation with these traits was observed for C18:2 as a percentage of total FA. In conclusion, FA concentration and profile of corn silage reflects to a great extent the FA composition of kernels and the proportion of grain in the silage. The variation in C18:2 across hybrids provides the opportunity to develop selection programs to decrease C18:2 in corn silage and grain. Selection based on C18:2 concentration as a percent of total FA is preferred as this trait did not correlate with other nutritional properties.

Key words: corn, milk fat depression, unsaturated fatty acids, corn silage

\section{INTRODUCTION}

Corn (Zea mays L.) whole-plant silage and grain make up the majority of contemporary lactating cow diets in the United States (Klopfenstein et al., 2013). Corn silage and high-moisture corn grain are commonly recognized as risk factors for biohydrogenation (BH)-induced milk fat depression (MFD), and many nutritionists cite higher rates of starch digestion, low effective fiber, or fiber digestion kinetics as the culprit. However, the increased risk may also be due to the amount or availability of UFA. 
Biohydrogenation-induced MFD occurs when specific intermediates of bacterial fatty acid (FA) metabolism escape the rumen and inhibit milk fat synthesis in the mammary gland (Bauman and Griinari, 2003). Much of the attention has been directed at linoleic acid (C18:2) $\mathrm{BH}$ because it is believed to be the parent compound for most of the bioactive trans FA that decreased milk fat (Jenkins, 2011). Indeed, diets rich in C18:2 increase the risk for BH-induced MFD (He and Armentano, 2011; He et al., 2012). Substitution of other FA for C18:2 may decrease risk; for example, milk fat was increased from 2.42 to $2.92 \%$ when cows were fed high C18:1 compared with high C18:2 sunflower seeds (Casper et al., 1988). Furthermore, addition of rumen-available supplements rich in $\mathrm{C} 18: 2$ (e.g., soybean oil) to lactating cow diets is a well-established model to produce $\mathrm{BH}$-induced MFD (Rico and Harvatine, 2013; Rico et al., 2015). Reducing rumen-available UFA, and especially C18:2, is commonly recommended to control the risk of $\mathrm{BH}$-induced MFD (Jenkins, 2011).

The predominant long-chain FA in corn silage and grain is commonly reported to be C18:2. These feeds have a low concentration of FA, but because of their high inclusion rate in lactating cow diets they contribute substantially to total UFA intake. Therefore, the increased risk of BH-induced MFD when feeding cornderived feeds may be associated with their contribution to $\mathrm{C} 18: 2$ intake.

Studies conducted over the past 3 decades have reported a considerable genetic diversity in corn FA concentration and profile (Widstrom and Jellum, 1975; Pamin et al., 1986). A literature search recovered a limited number of papers reporting FA profile of corn hybrids, but provided support for a reasonable range of C18:2 concentration (Table 1). Although these studies provide insights into variation in grain of various corn strains, a limited view of the variation in C18:2 concentration in whole-plant corn silage and grain of modern commercially available hybrids is available. Additionally, previous characterizations have reported that the majority of the FA in corn grain is in the germ, but we are not aware of a characterization of the contributions of FA to the whole plant. Our first objective was to characterize the contribution of individual plant parts to total FA in whole-plant corn silage. The second objective was to characterize the variation in FA profile in commercial corn silage and grain hybrids and evaluate the relationship between FA profile and other nutrients. Our hypothesis was that variation exists between hybrids that would allow for selection of hybrids with lower C18:2 concentration that would be expected to have a decreased risk of BH-induced MFD. During the course of the investigation, the effect of drying method (freeze drier and forced-air oven) on sample FA profile was assessed to allow comparison to the literature and between data sets and assist with commercial application in forage testing laboratories.

\section{MATERIALS AND METHODS}

\section{Sample Sets}

The initial characterization used samples from corn hybrid test plot from Pennsylvania (PA) using fresh whole-plant chopped corn from silage hybrids and grain from grain hybrids in 2013. Similar samples were collected from PA test plots in 2014 to replicate the findings. Lastly, through collaborations, corn silage samples from South Dakota test plots were analyzed to extend the characterization to other hybrids in a second region.

Samples from Pennsylvania were part of the Corn Silage Research Project, which is a research program conducted in a collaborative effort between the Professional Dairy Managers of Pennsylvania, Penn State University, and seed companies (www.pdmp.org/corn -silage-research-project). Pennsylvania samples came from research plots located in Blair and Centre County, PA, and were collected in 2013 and 2014 (Plant parts data set was collected in 2013 only, Table 2). In the fresh whole-plant chopped corn data set collected in 2013, 35 out of the 67 samples were cultivated in Lancaster County, PA, in a commercial test plot (Croplan, WinField Solutions LLC, Shoreview, MN). Samples from South Dakota were part of the Corn Silage Variety Trials and Crop Performance Testing project, which is a research program coordinated by the Department of Dairy Science and Extension, South Dakota State University. These hybrids were cultivated at the South Dakota State University Volga Research Farm, Brookings County, South Dakota (corn silage data set in Table 2).

\section{Sample Collection and Processing}

For determination of the FA concentration of individual plant parts, stalks were manually harvested from 4 different hybrids in quadruplicates (4 stalks/hybrid) at approximately $30 \%$ DM. Test plots were $5.5 \mathrm{~m}$ long, 4 rows wide, row spacing of $76 \mathrm{~cm}$, and seeded at density of 84,000 plants per hectare. The 4 stalks for each hybrid were randomly harvested from the central region of the 2 middle rows of one test plot. Each corn plant was individually separated into stalk, husk and shank, leaves, cob, and kernels. These samples were dried in a forced-air oven at $55^{\circ} \mathrm{C}$ for $48 \mathrm{~h}$ to determine DM content, ground to $1 \mathrm{~mm}$ with a Wiley Mill (Arthur H. 
Table 1. Summary of papers reporting variation in corn fatty acid profile

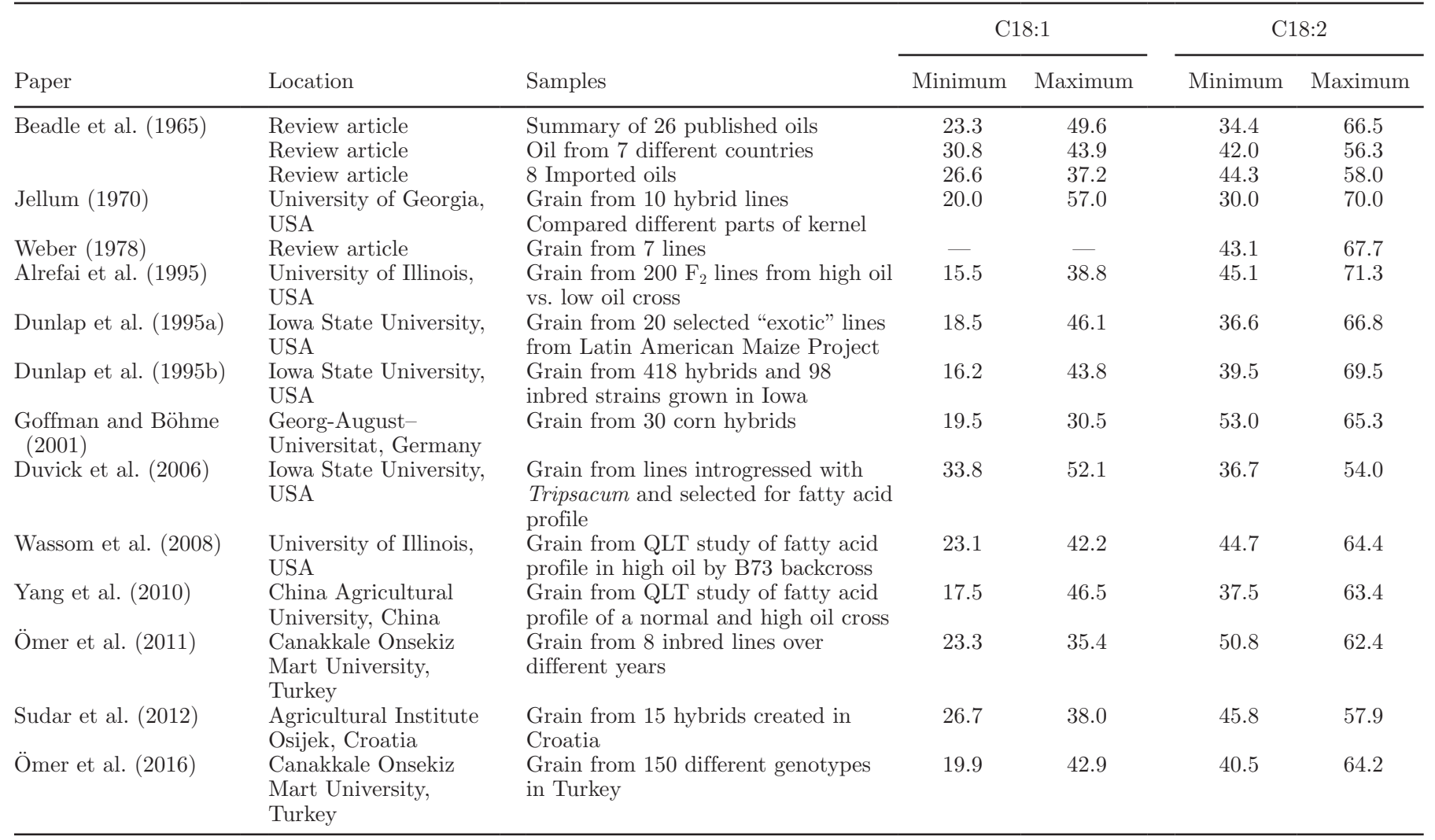

Thomas Co., Philadelphia, PA), and stored at $-20^{\circ} \mathrm{C}$ until FA analysis. Oven drying was selected because of the bulk of the samples.

In the PA fresh whole-plant chopped corn data set, corn hybrids were chopped using a Cibus TRM Wintersteiger plot harvester (Wintersteiger Inc., Salt Lake City, UT), approximately 500-g samples were collected at harvesting, immediately transported to the laboratory, and stored at $-20^{\circ} \mathrm{C}$ until freeze dried with a Virtis 3.5 L XL (The Virtis Co., Gardiner, NY) in a 5-step 52-h process. Samples were ground as described above and stored at $-20^{\circ} \mathrm{C}$ until $\mathrm{FA}$ analysis. In the 2013 crop year, 2 samples per hybrid were collected and one was oven dried (as described above) for a drying method comparison.

Corn grain samples were collected from PA grain hybrid test plots with a combine harvester, immediately transported to the laboratory, freeze dried, ground using a spinning blade coffee grinder (model 80333, Hamilton Beach, Glen Allen, VA), and stored at $-20^{\circ} \mathrm{C}$ until FA analysis.

Last, the characterization was extended to corn silage hybrids available from an experiment at South Dakota State University. Briefly, samples were collected from South Dakota hybrid test plots at approximately $35 \%$ DM by cutting plants from each replicated plot with

Table 2. Description of fresh whole-plant chopped corn, corn silage, and corn grain data sets in this manuscript

\begin{tabular}{lccll}
\hline Location & Harvested & No. of hybrids & Description/data set & Drying method \\
\hline Pennsylvania & Sep. 2013 & $4^{1}$ & Plant parts & Oven \\
Pennsylvania & Sep. 2013 & 67 & Fresh chopped whole plant & Freeze and oven \\
Pennsylvania & Sep. 2014 & 57 & Fresh chopped whole plant & Freeze \\
Pennsylvania & Nov. 2013 & 36 & Corn grain & Freeze \\
Pennsylvania & Nov. 2014 & 36 & Corn grain & Freeze \\
South Dakota & Oct. 2013 & $45^{3}$ & Corn silage & Oven \\
\hline
\end{tabular}

${ }^{1}$ Four replicates per hybrid $(\mathrm{n}=16)$.

${ }^{2}$ Fresh whole-plant chopped corn.

${ }^{3}$ Six mini-silo replicates per hybrid (total $\mathrm{n}=270$ ). 
a power cutter and chopping with a chipper/shredder before inoculation with silage fermentation additive and packing in 5-gallon (18.9 L) mini-silo buckets. The buckets were sealed with an air-tight lid and placed in storage for $90 \mathrm{~d}$. After the ensiling period, a sample from each silo was collected, dried in a forced-air oven at $55^{\circ} \mathrm{C}$ for $48 \mathrm{~h}$ and ground to $1-\mathrm{mm}$ (as described above).

All samples were analyzed for FA by the Harvatine Lab (Penn State University) under the same analytical protocol. Fatty acid methyl esters generated by a onestep methylation (Sukhija and Palmquist, 1988). Total FA concentration and FA profile were determined by GC as in Rico and Harvatine (2013). Proximate analysis of starch, NDF, and in vitro NDF digestibility was carried out by Cumberland Valley Analytical Services (Hagerstown, MD) for Pennsylvania samples and by Analab (Division of Agri-King Inc., Fulton, IL) for South Dakota samples.

\section{Statistical Analysis}

Drying methods (freeze dried vs. forced-air oven dried) were compared using Deming regression (MedCalc Software, Ostend, Belgium) to accommodate errors in both dimensions (Cornbleet and Gochman, 1979). Deming regressions are recommended for estimating bias and confidence intervals in method comparisons (Martin 2000). Freeze drying was considered the test method (Y) and oven drying the reference method (X).

Distribution (\% of total in plant) of DM, total FA, and selected FA (C16:0, C18:0, C18:1, C18:2, and C18:3) in plant parts was analyzed using the Fit Model procedure of JMP 12 (SAS Institute Inc., Cary, NC). The model included the fixed effect of part and the random effects of hybrid and replication nested within hybrid. Differences between plant parts were determined using a protected least significant difference mean separation $(\alpha=0.05)$. The geometric mean and standard deviation for parts within each hybrid are also reported in Supplemental Tables S1 and S2 (https://doi.org/10 .3168/jds.2017-12972).

Distribution of FA between corn hybrids was assessed using the Distribution option of JMP 12 and analyzed by data set (2013 fresh whole-plant chopped corn, 2014 fresh whole-plant chopped corn, corn grain, and corn silage). Statistical comparison between data sets is not possible because they do not contain the same hybrids. The South Dakota data set included replicated samples allowing determination of the variation due to hybrid by ANOVA that included the fixed effect of hybrid (JMP 12).

Relationship among FA was assessed using the Simple Linear Regression option of JMP and analyzed by data set (fresh whole-plant chopped corn and corn grain). Observations greater or smaller than 1.5 times the upper and lower quartile, respectively, or outside of \pm 3 Studentized residuals were considered outliers and removed from the analysis (Rousseeuw and Leroy, 2005). Statistical significance of slopes was declared at $P<0.05$. Correlation between FA and other traits (starch, NDF, and NDF digestibility) was assessed using the Multivariate option of JMP. The illustration of feeding diets containing corn silage with different C18:2 contents was developed using Microsoft Excel (Microsoft Corp., Redmond, WA).

\section{RESULTS AND DISCUSSION}

\section{Effect of Oven vs. Freeze Drying}

Sample handling and processing before analysis can bias FA profile. After harvesting, plant lipases cause rapid release of esterified UFA (Dewhurst et al., 2003), and the resulting free FA are more susceptible to degradation, including oxidation. Sukhija and Palmquist (1988) reported that although freeze drying and oven drying yielded similar results for FA concentration and composition of many feedstuffs, oxidation of PUFA may occur with oven drying of some samples. We conducted a comparison of freeze drying and oven drying to determine the optimal procedure, allow comparison to other literature and data sets, and aid application of reported freeze-dried data to commercial analysis laboratories that do not have the capacity to freeze dry.

Deming regression analysis was used to compare the FA profile of fresh whole-plant chopped corn samples subjected to oven drying or freeze drying. Deming regression was used for this method-comparison, as simple linear regression does not account for measurement error in both the independent and dependent variables (Cornbleet and Gochman, 1979). Briefly, in Deming regression, if the confidence interval for the slope does not contain the 1 , there is a proportional difference between the 2 methods. If the confidence interval for the intercept does not contain 0 , the methods differ by a constant amount. In this study, no difference between the 2 methods was observed for sample DM and concentration of C16:0, C18:2, and C18:3 based on the confidence intervals of the intercept and slope (overlap with 0; Table 3). However, a slope bias was observed for C18:0 (slope $=0.83$; Table 3 ), as a greater concentration of C18:0 was detected in oven-dried samples, particularly when the concentration of C18:0 increased (Figure 1A). An intercept and slope bias was observed for C18:1 (intercept $=-4.72$; Table 3 ), although the magnitude of the difference is rather small (e.g., 0.375 percentage points at $3.5 \% \mathrm{C} 18: 0)$. The intercept indi- 
Table 3. Comparison of $55^{\circ} \mathrm{C}$ forced-air oven to freeze drying of fresh whole-plant chopped corn using Deming regression ${ }^{1}$

\begin{tabular}{|c|c|c|c|c|c|c|c|c|c|}
\hline \multirow[b]{3}{*}{ Item } & \multirow[b]{3}{*}{$\mathrm{R}^{2}$} & \multicolumn{4}{|c|}{ Intercept (g/100 g) } & \multicolumn{4}{|c|}{ Slope (g/100 g) } \\
\hline & & \multirow[b]{2}{*}{ Intercept } & \multirow[b]{2}{*}{$\mathrm{SE}$} & \multicolumn{2}{|c|}{$95 \%$ CI } & \multirow[b]{2}{*}{ Slope } & \multirow[b]{2}{*}{$\mathrm{SE}$} & \multicolumn{2}{|c|}{$95 \% \mathrm{CI}$} \\
\hline & & & & Lower & Upper & & & Lower & Upper \\
\hline Total fatty acids & 0.88 & 0.75 & 2.21 & -3.67 & 5.17 & 1.01 & 0.07 & 0.88 & 1.14 \\
\hline C16:0 & 0.86 & -0.01 & 0.67 & -1.35 & 1.34 & 0.96 & 0.04 & 0.88 & 1.04 \\
\hline C18:0 & 0.88 & 0.22 & 0.16 & -0.9 & 0.54 & 0.83 & 0.07 & 0.69 & 0.96 \\
\hline C18:3 & 0.63 & 0.94 & 0.93 & -0.93 & 2.80 & 1.11 & 0.17 & 0.77 & 1.44 \\
\hline
\end{tabular}

${ }^{1}$ Analysis based on Pennsylvania fresh whole-plant chopped corn samples collected in 2013. Freeze drying was considered the test method (Y) and oven drying the reference method $(\mathrm{X})$. The coefficient of variation used in the analysis was DM $=3.0 \%, \mathrm{C} 16: 0=0.8 \%, \mathrm{C} 18: 0=0.8 \%$, cis-9 $\mathrm{C} 18: 1=1.0 \%, \mathrm{C} 18: 2 \mathrm{n}-6=1.0 \%$, and $\mathrm{C} 18: 3 \mathrm{n}-3=3.5 \%$.

cated that a higher concentration of $\mathrm{C} 18: 1$ was detected in oven-dried samples when C18:1 was low; however, the slope was 1.2 , resulting in a shift to similar concentrations when the concentration of $\mathrm{C} 18: 1$ was high (Figure 1B).

Oven drying at lower temperatures and for prolonged time decreased the concentration of $\mathrm{C} 18: 2$ in soybeans (Stewart et al., 2003) and increased the concentration of C18:0 in timothy hay (Arvidsson et al., 2009). Our observation of increased concentration of C18:0 in ovendried samples may be explained by enrichment due to numerical decrease in C18:2 or C18:3 in oven-dried fresh whole-plant chopped corn samples. The column and procedure used allows clear separation of trans isomers and it is unlikely that the increase in C18:0 and C18:1 was due to coelution. Freeze-dried samples were used when possible in the current characterization because the goal was to characterize the true FA profile. Freeze drying is not possible in many commercial analysis settings and the bias described above should be considered when interpreting oven-dried samples. Others have noted that drying time is more important than drying temperature and higher temperatures; shorter duration drying may be advantageous when it is necessary to oven dry (Stewart et al., 2003). Importantly, air, light, and heat exposure should be minimized during sample storage before and after drying.

\section{Fatty Acid Profile of Each Part of a Corn Plant}

Fatty acid concentration in different parts of the corn kernel is well described with the majority of the FA found in the germ (Jellum, 1970). However, distribution of FA in the whole plant has not been previously characterized to our knowledge. We separated the corn plant into 5 major parts (stalk, husk and shank, leaves, cob, and kernels) and characterized the FA concentration and profile of each individual part. Two of the hybrids selected were conventional hybrids, one was

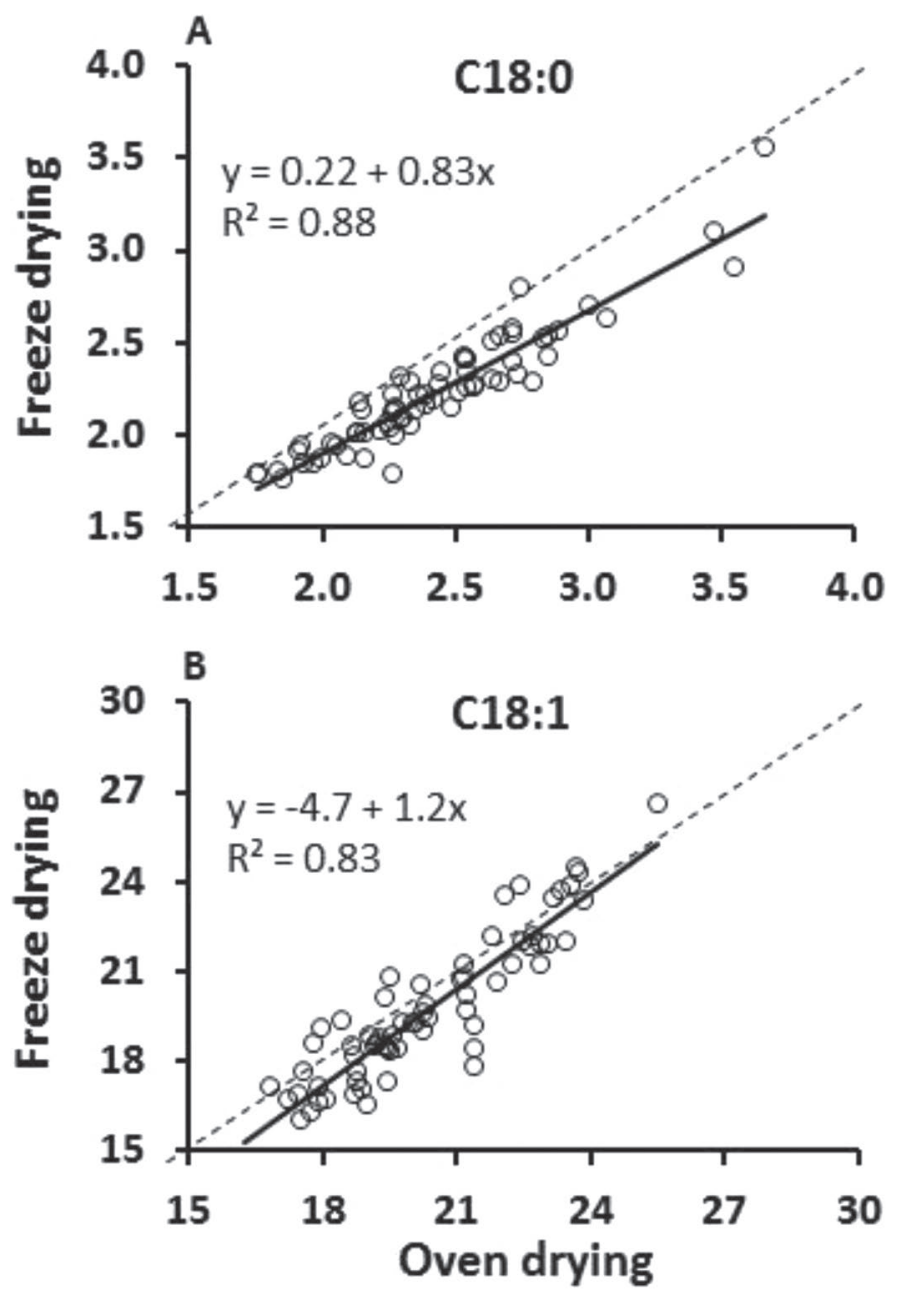

Figure 1. Effect of freeze drying or oven drying on the concentration of stearic acid (C18:0, panel A) and oleic acid (C18:1, panel B) in fresh whole-plant chopped corn. Data from 67 hybrids grown in test plots cultivated in Pennsylvania in 2013. Dashed line $\mathrm{X}=\mathrm{Y}$, and solid line is the fitted Deming regression line. 
a leafy variety, and one was a brown midrib (BMR) variety to represent some of the major hybrids available for corn silage production (Supplemental Table S1; https://doi.org/10.3168/jds.2017-12972). A hybrid by plant part interaction was not the goal of the current work and hybrid was modeled as a random effect. However, the FA distribution among plant parts followed a similar pattern across hybrids, and means of each hybrid are reported in Supplemental Tables S2 and S3 (https://doi.org/10.3168/jds.2017-12972).

Total FA concentration averaged 4.02, 1.94, 0.35, 0.46 , and $0.53 \%$ of DM in kernels, leaves, stalk, cob, and husk and shank, respectively (Supplemental Table S2; https://doi.org/10.3168/jds.2017-12972). As a percent of whole-plant DM, kernels were $44.1 \%$, leaves were $13.2 \%$, stalk was $31.4 \%$, cob was $7.5 \%$, and husk and shank was $3.7 \%$. Due to differences in their proportion of the plant DM and FA concentration, $80.5 \%$ of the total FA were found in the kernels, $11.8 \%$ in the leaves, $5.1 \%$ in the stalk, and less than $2 \%$ in the cob and husk and shank (Table 4). Palmitic (C16:0), oleic (C18:1), linoleic (C18:2), and $\alpha$-linolenic (C18:3) acids accounted for more than $80 \%$ of total FA regardless of the part of the plant; therefore, we will focus our discussion on these $4 \mathrm{FA}$. The FA composition was unique to the plant part, with the majority of the $\mathrm{C} 16: 0$ (76.4\%), C18:1 (96.8\%), and C18:2 (92.5\%) found in the kernels and the majority of the C18:3 $(71.0 \%)$ found in the leaves (Table 4). This is in part due to the role that each one of these components plays in the corn plant. As reported by Weber (1978), lipids in the chloroplasts of leaves function as membrane constituents and phospholipids and glycolipids rich in C18:3 are the predominant lipids. Additionally, the leaf triglycerides have a higher concentration of C18:3 compared with lipids of other plant parts (Weber, 1978). On the other hand, triglycerides are the predominant lipids in the kernels where they function as storage lipids and are mainly rich in C18:2 (Weber, 1978).

Because the majority of the whole-plant FA in general, and C18:2 specifically, is contained in the grain, selection of corn silages for lower C18:2 must focus on decreasing its concentration in the kernel and data available on grain FA profile can be used to drive the selection process. A reasonable amount of research is available on FA concentration and profile of corn kernels (summarized in Table 1), as well as the genetic variation around these traits and the inheritance of specific FA (e.g., Alrefai et al., 1995; Beadle et al., 1965; Pamin et al., 1986).

\section{Fatty Acid Profile of Corn Silage Hybrids}

The difficulty in interpreting the literature is that much of the published data are from research strains or older commercial hybrids and focus on hybrids for grain production. Thus, it was necessary to characterize contemporary commercial silage hybrids. This characterization was done with whole-plant corn silage as that is what is fed and not only characterizes the variation of C18:2, but also allows correlation of FA profile with other nutritional properties relevant to dairy ration formulation.

First, fresh whole-plant chopped corn and grain from PA silage and grain hybrid test plots, respectively, were characterized in 2013 and 2014. These were analyzed as 2 separate data sets as varieties were different between years, precluding statistical comparison across years. However, it provides insight into the repeatability across growing years. In the fresh whole-plant chopped corn C18:2 averaged $48.7 \%$ of $\mathrm{FA}$ in the 2013 data set (percentiles: 10 th $=45.2,90$ th $=52.2$ ) and $48.0 \%$

Table 4. Distribution of DM, total fatty acids (FA), and the 5 major FA in corn plant parts ${ }^{1}$

\begin{tabular}{lccccccc}
\hline \% of total & & & & Husk and \\
shank & Kernels & Stalk & Leaves & Cob & SEM $^{3}$ & $P$-value \\
\hline $\mathrm{DM}^{5}$ & $44.1^{\mathrm{a}}$ & $31.4^{\mathrm{b}}$ & $13.2^{\mathrm{c}}$ & $7.51^{\mathrm{d}}$ & $3.66^{\mathrm{e}}$ & 0.90 & $<0.001$ \\
Total FA & $80.5^{\mathrm{a}}$ & $5.05^{\mathrm{c}}$ & $11.8^{\mathrm{b}}$ & $1.67^{\mathrm{d}}$ & $0.97^{\mathrm{d}}$ & 0.57 & $<0.001$ \\
$\mathrm{C} 16: 0^{6}$ & $76.4^{\mathrm{a}}$ & $7.69^{\mathrm{c}}$ & $12.4^{\mathrm{b}}$ & $2.35^{\mathrm{d}}$ & $1.14^{\mathrm{d}}$ & 0.61 & $<0.001$ \\
$\mathrm{C} 18: 0$ & $65.7^{\mathrm{a}}$ & $14.1^{\mathrm{b}}$ & $16.0^{\mathrm{b}}$ & $2.15^{\mathrm{c}}$ & $2.14^{\mathrm{c}}$ & 1.08 & $<0.001$ \\
$\mathrm{C} 18: 1$ & $96.8^{\mathrm{a}}$ & $0.70^{\mathrm{b}}$ & $0.87^{\mathrm{b}}$ & $1.06^{\mathrm{b}}$ & $0.54^{\mathrm{b}}$ & 0.23 & $<0.001$ \\
$\mathrm{C} 18: 2$ & $92.5^{\mathrm{a}}$ & $3.28^{\mathrm{b}}$ & $1.92^{\mathrm{c}}$ & $1.55^{\mathrm{cd}}$ & $0.73^{\mathrm{d}}$ & 0.33 & $<0.001$ \\
$\mathrm{C} 18: 3$ & $17.4^{\mathrm{b}}$ & $9.84^{\mathrm{c}}$ & $71.0^{\mathrm{a}}$ & $1.00^{\mathrm{d}}$ & $0.80^{\mathrm{d}}$ & 0.78 & $<0.001$ \\
\hline
\end{tabular}

${ }^{\mathrm{a}-\mathrm{e}}$ Means that do not share a superscript differ $(P<0.05)$.

${ }^{1}$ Analysis based on 4 plant replicates of 4 different hybrids from the Pennsylvania plant parts subset.

${ }^{2}$ Percentage of total in the plant.

${ }^{3}$ Pooled SEM.

${ }^{4}$ Effect of plant part.

${ }^{5} \mathrm{LSM}$ with different superscript across row differ at $P<0.05$ according to Student's $t$-test.

${ }^{6} \mathrm{C} 16: 0$ (palmitic), C18:1 (oleic), C18:2 (linoleic), and C18:3 ( $\alpha$-linolenic acid). 
Table 5. Concentration of major fatty acids (FA) in fresh whole-plant chopped corn and corn grain from commercial hybrids grown in test plots in Pennsylvania ${ }^{1}$

\begin{tabular}{|c|c|c|c|c|c|c|c|c|}
\hline Item $^{2}$ & \multicolumn{4}{|c|}{2013} & \multicolumn{4}{|c|}{2014} \\
\hline \multicolumn{9}{|c|}{$\begin{array}{l}\text { Fresh whole-plant chopped corn } \\
\% \text { of DM }\end{array}$} \\
\hline Total FA & 2.54 & 0.41 & 2.00 & 3.10 & 2.61 & 0.23 & 2.38 & 2.90 \\
\hline C16:0 & 16.2 & 1.22 & 14.8 & 17.8 & 15.8 & 0.68 & 14.9 & 16.9 \\
\hline C18:1 & 19.6 & 2.52 & 16.7 & 23.5 & 18.4 & 1.85 & 16.4 & 20.5 \\
\hline C18:2 & 48.7 & 3.00 & 45.2 & 52.2 & 48.0 & 2.08 & 44.1 & 49.4 \\
\hline C18:3 & 7.83 & 2.69 & 4.24 & 10.8 & 7.60 & 1.58 & 5.52 & 10.1 \\
\hline \multicolumn{9}{|l|}{ Corn grain } \\
\hline \multicolumn{9}{|l|}{$\%$ of $\mathrm{DM}$} \\
\hline Total FA & 3.56 & 0.27 & 3.00 & 4.20 & 3.73 & 0.31 & 3.26 & 4.14 \\
\hline C18:3 & 1.64 & 0.13 & 1.50 & 1.80 & 1.73 & 0.10 & 1.59 & 1.86 \\
\hline
\end{tabular}

${ }^{1}$ Analysis based on freeze-dried samples from the PA fresh whole-plant chopped corn and corn grain data sets.

${ }^{2}$ Palmitic (C16:0), oleic (C18:1), linoleic (C18:2n-6), and $\alpha$-linolenic (C18:3) acid.

of FA in the 2014 (percentiles: 10th $=44.1,90 \mathrm{th}=$ 49.4; Table 5). As expected, C18:2 was higher in corn grain, averaging $57.5 \%$ of total $\mathrm{FA}$ in the 2013 data set (percentiles: 10 th $=53.4,90$ th $=60.8$ ) and $56.1 \%$ of total FA in the 2014 (percentiles: 10th $=53.5,90 \mathrm{th}$ $=59.4$ ). Despite a small difference in the averages between 2013 and 2014, the range of C18:2 concentration among hybrids in both fresh chopped whole plants and grain was similar between the 2 yr (Table 5). Wassom et al. (2008) previously reported that growing year is a smaller source of variation affecting FA composition of corn grain compared with hybrid. Additionally, environmental factors such as temperature, planting date, and fertilization have been suggested to have a much smaller influence on corn FA profile compared with genotypic factors (Jellum and Marion, 1966; Jahndeesbach et al., 1975).

South Dakota State University had also previously conducted a commercial corn hybrid plot test. To extend the characterization to another region, a collaboration was established to analyze FA profile of 270 corn silage samples available from 45 different hybrids (Table 2). In this experiment replicate plots had been ensiled. Ensiling does not change total FA concentration of corn silage and has a minimal effect on the proportions of C18:2 and C18:3 (Alves et al., 2011), allowing comparison to fresh whole-plant samples discussed above. Importantly, the objective was not to broaden our characterization of the variation between hybrids and not to study the effect of ensiling. In South Dakota corn silage samples, the concentration of C18:2 averaged $45.4 \%$ of total FA (percentiles: 10 th $=39.4$, 90th $=50.2$, Table 6 ) and C18:2 concentration averaged $1.1 \%$ of DM (percentiles: 10th $=0.76,90 \mathrm{th}=$ 1.41, Table 6). The range in C18:2 concentration was similar to that observed in fresh whole-plant chopped corn samples from the Pennsylvania test plots. Importantly, the corn silages were grown in a different region and verify the diversity in commercial hybrids.

The variation due to hybrid was determined in the South Dakota data set by ANOVA analysis. Based on model sum of squares, hybrid explained over $44 \%$ of the

Table 6. Concentration of major fatty acids (FA) in corn silage from commercial hybrids grown in test plots in South Dakota ${ }^{1}$

\begin{tabular}{lcccc}
\hline & & & \multicolumn{2}{c}{ Percentile } \\
\cline { 4 - 5 } Fatty acid $^{2}$ & Mean & SD & 10 th & 90 th \\
\hline \% of DM & & & & \\
$\quad$ Total FA & 1.6 & 0.63 & 1.95 & 3.2 \\
C18:2 & & 0.28 & 0.76 & 1.41 \\
\% of total FA & 19.0 & 1.17 & 17.6 & 20.5 \\
C16:0 & 22.2 & 2.28 & 19.5 & 24.8 \\
C18:1 & 45.4 & 5.95 & 39.4 & 50.2 \\
C18:2 & 6.84 & 2.74 & 3.46 & 10.3 \\
C18:3 & &
\end{tabular}

${ }^{1}$ Analysis based on samples from South Dakota corn silage data set. ${ }^{2}$ Palmitic (C16:0), oleic (C18:1), linoleic (C18:2n-6), and $\alpha$-linolenic (C18:3) acid. 
variation in total FA concentration, $42 \%$ of the variation in $\mathrm{C} 18: 2$ as a percent of DM, and $35 \%$ of variation in $\mathrm{C} 18: 2$ as a percent of FA.

The variation in C18:2 concentration in corn grain observed in the PA data sets (Table 5) are smaller than the values of 39.5 to $69.5 \%$ reported by Dunlap et al. (1995b), 30 to $70 \%$ by Jellum (1970), and 43.1 to $67.7 \%$ by Weber (1978). It is worth noting that these studies contained a broad array of genetics including low- and high-oil hybrids, which increases the variation in total FA and C18:2 concentration. The current data sets evaluated a set of commercial hybrids, and current hybrids appear to have much less variation in C18:2 than available in the broader corn population. Corn grain samples in the current experiment were also harvested from the middle 2 rows of the 4 row test plots to reduce cross-pollination, but some cross-pollination may have occurred and would be expected to reduce the variation between hybrids. Nonetheless, we still observed on average a 33\% difference between the 10th and 90th percentiles for C18:2 among corn grain hybrids (1.8 vs. $2.4 \%$ of DM). Concentration of C18:2 in corn hybrids expressed as a percent of DM is most important to a ration as it affects the amount of C18:2 consumed.

Overall, the current study demonstrated that variation exists among hybrids for C18:2 concentration in fresh whole-plant chopped corn, corn silage, and corn grain and highlights the potential for further selection of varieties low in C18:2. Regulation of corn FA profile is not as well studied as oilseeds, but FA concentration and profile is a highly heritable trait in corn (Widstrom and Jellum, 1975; Pamin et al., 1986; Alrefai et al., 1995). Additionally, previous work has identified QTL and SNP useful for selection of specialized FA composition (Wassom et al., 2008). However, many of the previous corn FA breeding efforts have focused on producing a high oil and high oleic acid corn for oil production. The goal of a low BH-induced MFD corn would be low to moderate oil level and low C18:2. This will require a different selection goal than most previous specialty oil hybrids.

\section{Regression Analysis of Fatty Acids}

A positive correlation has been reported between $\mathrm{C} 18: 2(\mathrm{~g} / \mathrm{kg}$ of DM) and total FA $(\mathrm{g} / \mathrm{kg}$ of DM) in corn silage (Khan et al., 2012). This result is not surprising as there is autocorrelation because total FA is used to calculate C18:2 concentration on a DM basis. The unbiased method to assess the relationship is to plot C18:2 as a percent of total FA against total FA (\% of DM or $\mathrm{g} / \mathrm{kg}$ of $\mathrm{DM})$. In the current sample data sets, no correlation was observed between C18:2 concentration and total FA concentration in both fresh whole-plant
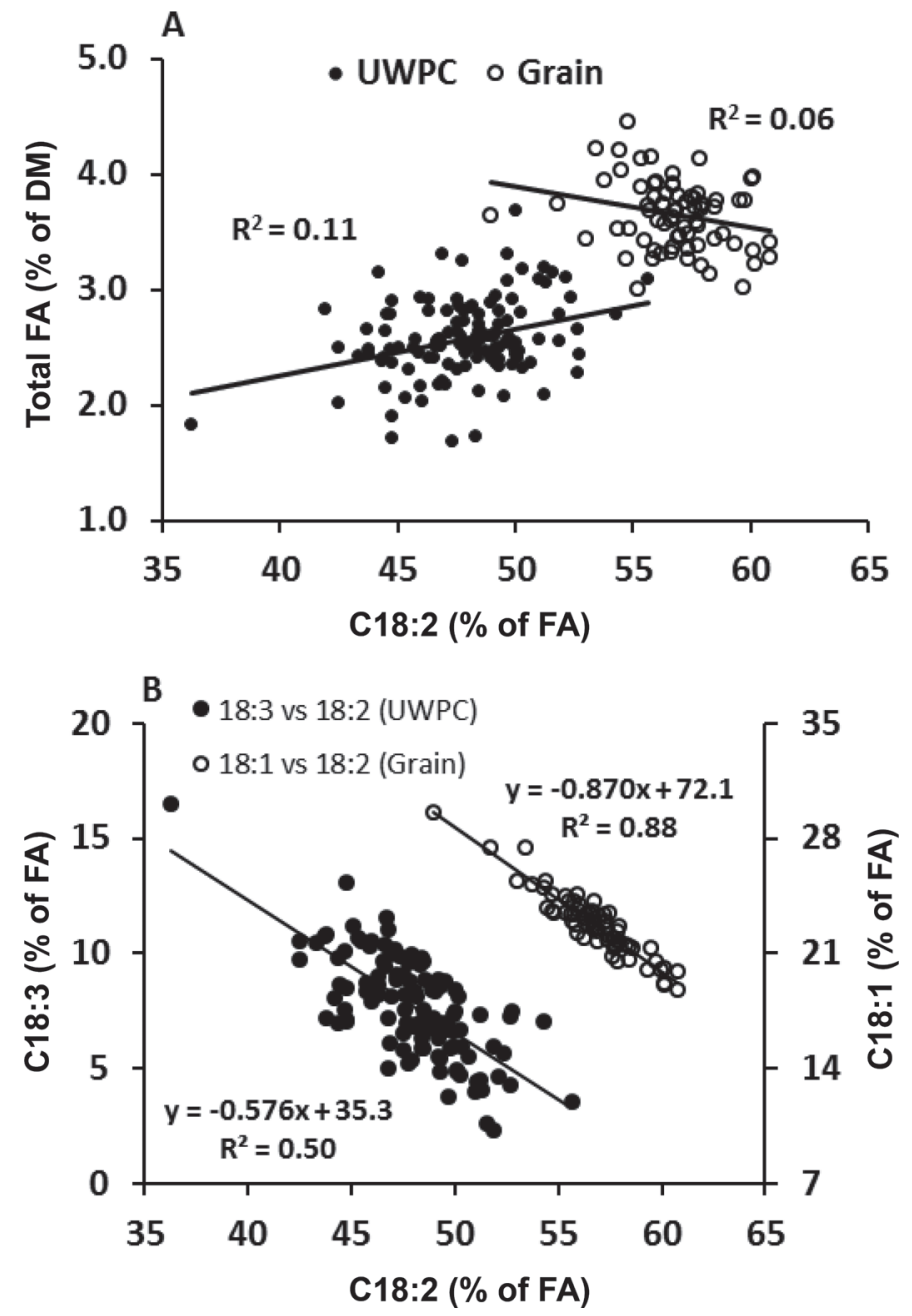

Figure 2. Relationship between fatty acids (FA) in fresh wholeplant chopped corn (UWPC) and corn grain hybrids. (A) Relationship of $\mathrm{C} 18: 2$ (\% of $\mathrm{FA})$ versus total FA in Pennsylvania UWPC $(\mathrm{n}=$ $124)$ and Pennsylvania corn grain $(\mathrm{n}=72)$. (B) Relationship of concentration of C18:2 versus C18:3 as a percent of FA in Pennsylvania UWPC ( $\mathrm{n}=120)$, and C18:2 versus C18:1 in Pennsylvania corn grain $(\mathrm{n}=69)$. All samples were freeze dried. Observations outside of \pm 3 Studentized residuals were removed. Regression lines were not significant in panel A $(P>0.35$ for both $)$, but significant at $P<0.001$ in both equations in panel $\mathrm{B}$.

chopped corn and corn grain (Figure 2, panel A). This suggests that selection of hybrids with low $\mathrm{C} 18: 2$ based on FA concentration ( $\mathrm{C} 18: 2$ as \% of total FA) would not reduce silage total long-chain FA, which is particularly important as a decrease in FA content decreases the energy value of corn silage and decreased fat in the kernel may affect germination or early growth as the lipid is an energy source for the embryo.

A relationship between FA was also investigated using PA fresh whole-plant chopped corn and corn grain data sets. An increase in the concentration of C18:2 was associated with a decrease in C18:3 in fresh whole- 
Table 7. Pearson correlation coefficient for the association of total fatty acids (FA), linoleic acid (C18:2), starch, NDF, and either 24- or 30-h NDF digestibility (NDFD24 and NDFD30, respectively) ${ }^{1}$

\begin{tabular}{lccccccc}
\hline & \multicolumn{3}{c}{ Pennsylvania silages } & & \multicolumn{3}{c}{ South Dakota silages } \\
\cline { 2 - 3 } \cline { 6 - 8 } Fatty acid & Starch & NDF & NDFD24 & & Starch & NDF & NDFD30 \\
\hline $\begin{array}{l}\text { \% of DM } \\
\text { Total FA }\end{array}$ & $0.25^{*}$ & $-0.36^{*}$ & 0.03 & & $0.41^{*}$ & $-0.47^{*}$ & $0.25^{*}$ \\
C18:2 & $0.28^{*}$ & $-0.27^{*}$ & 0.05 & & $0.51^{*}$ & $-0.57^{*}$ & $0.22^{*}$ \\
$\begin{array}{l}\text { \% of total FA } \\
\text { C18:2 }\end{array}$ & 0.18 & 0.08 & 0.03 & & -0.05 & 0.06 & -0.01 \\
\hline
\end{tabular}

${ }^{1}$ Analysis based on 87 fresh whole-plant chopped corn from Pennsylvania and 266 silages from South Dakota test plots. Only freeze-dried samples in Pennsylvania data sets were included in this analysis.

${ }^{2}$ Pennsylvania silages $=24-\mathrm{h}$ NDFD and South Dakota silages $=30-\mathrm{h}$ NDFD.

$* P<0.05$ for the Pearson correlation coefficient.

plant chopped corn (Figure 2, panel B). This is likely due to different proportions of leaves and grain among hybrids, and to a lesser extent, difference in plant maturity at harvesting. Increasing maturity decreases the concentration of $\mathrm{C} 18: 3$ in leaves due to tissue senescence and also increases the contribution of grain to total silage DM and C18:2 concentration (Khan et al., 2012). Hybrids were similar in expected days to maturity and were planted and harvested on the same day. In the corn grain data set, the concentration of C18:2 was negatively correlated with $\mathrm{C} 18: 1$ concentration (Figure 2, panel B). This strong negative correlation between the levels of $\mathrm{C} 18: 1$ and $\mathrm{C} 18: 2$ was previously observed in corn oil (Jellum, 1970; Pamin et al., 1986) and is expected to be explained by decreased activity of the $\mathrm{n}-6$ desaturase enzyme, which converts C18:1 to C18:2 by inserting a double bond at the $\mathrm{n}-6$ position (Alrefai et al., 1995). Therefore, an ideal way to decrease C18:2 and risk of BH-induced MFD would be to select against n- 6 desaturase activity and identify high C18:1 hybrids with moderate fat levels. Traditional and genetic modification plant breeding programs have been very successful in development of high C18:1 and low C18:2 sunflower seeds, safflower seeds, rapeseeds, and soybeans.

Pearson correlation analysis was carried out in the PA fresh whole-plant chopped corn and the South Dakota corn silage data sets to evaluate possible associations between C18:2 and other nutritional properties in corn silage. Total FA and C18:2 concentration (\% of DM) were positively correlated with starch and negatively correlated with NDF in both fresh whole-plant chopped corn and corn silage (Table 7). This was expected and likely explained by the proportion of grain in the silage. Additionally, total FA and C18:2 concentration (\% of DM) were positively correlated with NDF digestibility in both data sets (Table 7). This is probably because of the positive correlations between total FA and starch, and between starch and NDF digestibility. On the contrary, C18:2 as a percentage of total FA was not correlated with starch, NDF, or NDF digestibility in both fresh whole-plant chopped corn and corn silage (Table 7). Overall, results from the correlation analysis suggest that selection of hybrids based on C18:2 concentration (\% of DM), which is tightly associated with silage total FA, could result in decreased starch content and perhaps reduced NDF digestibility of the corn silage. However, selection of hybrids low in C18:2 as a percent of FA is less likely to adversely affect other nutritional properties (e.g., starch and NDF).

\section{Effect on C18:2 Intake in Dairy Cows}

To better understand the potential effect of differences in corn silage FA concentration and profile on C18:2 intake of the cow, a simple simulation was conducted. The simulation was run using the average and the 10th and 90th percentiles of C18:2 as a percent of DM $(1.2,0.9$, and $1.6 \%$ of DM, respectively) found in fresh whole-plant chopped corn (PA samples, crop year 2013, Table 5) with 3 levels of corn silage feeding (30, 42 , and $54 \%$ of diet DM) and $25 \mathrm{~kg} / \mathrm{d}$ of DMI. The difference between feeding corn silage at the 10th and 90th percentile is $52.5,73.5$, and $94.5 \mathrm{~g} / \mathrm{d}$ of C18:2 intake when feeding 30,42 , and $54 \%$ of DM, respectively (Figure 3). Importantly, this is the corn silage contribution only, and an additional benefit would be observed in combination with low C18:2 corn grain and corn byproducts. This demonstrates that selection of a low C18:2 corn hybrids would decrease rumen C18:2 load, which would be expected to decrease the risk of $\mathrm{BH}$-induced MFD.

Last, results from this study should encourage analysis of FA in corn silage and corn co-products when these feeds make up significant portion of the DM in the lactating cow diet. Although the C18:2 present in feedstuffs is extensively biohydrogenated in the rumen, it does provide an essential FA to the cow. Importantly, 


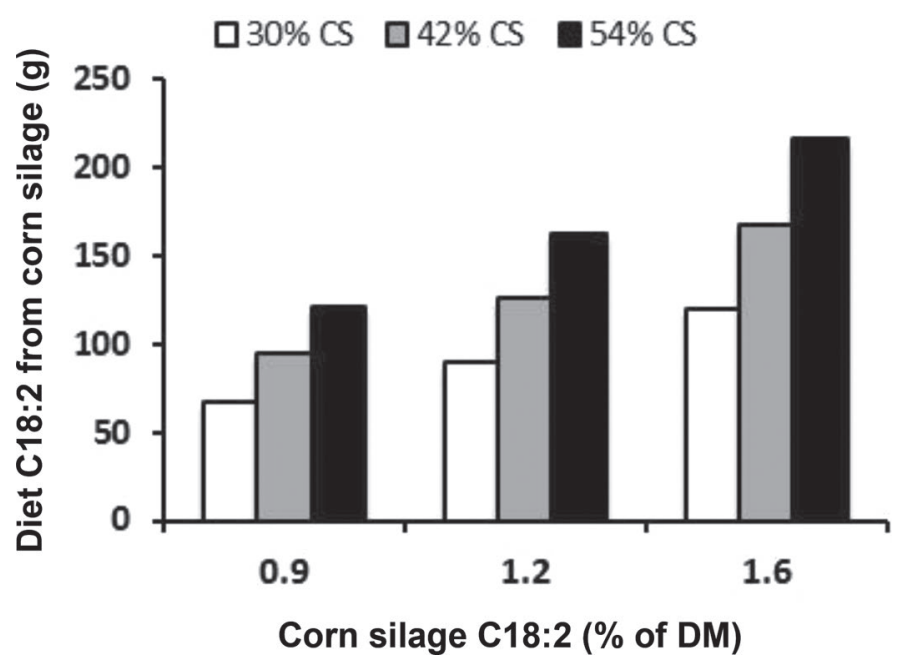

Figure 3. Illustration of the effect of feeding corn silages (CS) with different linoleic acid (C18:2) concentrations (average, and 10th and 90th percentiles from the Pennsylvania data set of fresh whole-plant chopped corn from year 2013) on the intake of C18:2 from a basal diet when the silage is fed at 3 inclusion levels $(30,42$, and $54 \%$ of diet DM). Simulation is based on $25 \mathrm{~kg} / \mathrm{d}$ of DMI.

the amount of absorbed C18:2 required by the cow is not known and is difficult to determine. It is reasonable to recommend that the LA intake should meet the requirement, but not be provided in amounts that increase the risk of MFD.

\section{CONCLUSIONS}

Freeze drying and forced-air oven drying yielded comparable results for 18:2, although small differences in C18:0 and C18:1 were observed. The kernel is the main contributor of total FA and C18:2 in wholeplant corn silage and leaves, stalk, cob, and husk and shank contribution is comparatively low. Therefore, FA concentration and profile of corn silage reflects to a great extent the FA composition of kernels and the proportion of grain in the silage. Variation in C18:2 content and concentration was found in contemporary corn silage and grain hybrids. The variation in C18:2 appeared consistent across years, similar between fresh whole-plant chopped corn and corn silages, and seemed to be attributed mainly to hybrid differences. Genetic variation in current hybrids and published strains provides the opportunity to develop selection programs to decrease C18:2. Selection based on C18:2 concentration as a percent of total FA is preferred as this trait did not correlate with total FA, starch, or NDF and could be achieved by selecting for increased C18:1. The variation between current hybrids is expected to have functional implication for risk of BH-induced MFD. Selecting hybrids with lower C18:2 is expected to reduce the risk and allow inclusion of other MFD risk factors that may increase efficiency or profitability.

\section{ACKNOWLEDGMENTS}

The help of students from South Dakota State University and other members of the Harvatine laboratory (Penn State University) with sample harvesting and ensiling is greatly appreciated. We want to thank the field specialists working with Greg Roth in the Department of Plant Science at Penn State University. We greatly appreciate Croplan, WinField Solutions, LLC for providing samples from the Lancaster test plot and the assistance of David Weakly (Croplan, WinField Solutions) for coordinating.

\section{REFERENCES}

Alrefai, R., T. G. Berke, and T. R. Rocheford. 1995. Quantitative trait locus analysis of fatty acid concentrations in maize. Genome 38:894-901.

Alves, S., A. Cabrita, E. Jerónimo, R. Bessa, and A. Fonseca. 2011. Effect of ensiling and silage additives on fatty acid composition of ryegrass and corn experimental silages. J. Anim. Sci. 89:2537-2545.

Arvidsson, K., A. M. Gustavsson, and K. Martinsson. 2009. Fatty acids in forages: A comparison of different pre-treatments prior to analysis. Anim. Feed Sci. Technol. 151:143-152.

Bauman, D. E., and J. M. Griinari. 2003. Nutritional regulation of milk fat synthesis. Annu. Rev. Nutr. 23:203-227.

Beadle, J. B., D. Just, R. Morgan, and R. Reiners. 1965. Composition of corn oil. J. Am. Oil Chem. Soc. 42:90-95.

Casper, D. P., D. Schingoethe, R. Middaugh, and R. Baer. 1988. Lactational responses of dairy cows to diets containing regular and high oleic acid sunflower seeds. J. Dairy Sci. 71:1267-1274.

Cornbleet, P. J., and N. Gochman. 1979. Incorrect least-squares regression coefficients in method-comparison analysis. Clin. Chem. 25:432-438.

Dewhurst, R. J., N. Scollan, M. Lee, H. Ougham, and M. Humphreys. 2003. Forage breeding and management to increase the beneficial fatty acid content of ruminant products. Proc. Nutr. Soc. 62:329 336.

Dunlap, F. G., P. J. White, and L. M. Pollak. 1995a. Fatty acid composition of oil from exotic corn breeding materials. J. Am. Oil Chem. Soc. 72:989-993.

Dunlap, F. G., P. J. White, L. M. Pollak, and T. J. Brumm. 1995b. Fatty acid composition of oil from adapted, elite corn breeding materials. J. Am. Oil Chem. Soc. 72:981-987.

Duvick, S. A., L. M. Pollak, J. W. Edwards, and P. J. White. 2006. Altering the fatty acid composition of Corn Belt corn through Tripsacum introgression. Maydica 51:409.

Goffman, F. D., and T. Böhme. 2001. Relationship between fatty acid profile and vitamin E content in maize hybrids (Zea mays L.). J. Agric. Food Chem. 49:4990-4994.

He, M., and L. Armentano. 2011. Effect of fatty acid profile in vegetable oils and antioxidant supplementation on dairy cattle performance and milk fat depression. J. Dairy Sci. 94:2481-2491.

He, M., K. Perfield, H. Green, and L. Armentano. 2012. Effect of dietary fat blend enriched in oleic or linoleic acid and monensin supplementation on dairy cattle performance, milk fatty acid profiles, and milk fat depression. J. Dairy Sci. 95:1447-1461.

Jahndeesbach, W., R. Marquard, and M. Heil. 1975. Investigations concerning fat quality in corn of German derivation with special consideration of linoleic acid content. Eur. Food Res. Technol. 159:271-278.

Jellum, M. D. 1970. Fatty-acid composition of oil from four kernel fractions of corn (Zea mays L.) inbred lines. Cereal Chem. 47:549-558. 
Jellum, M. D., and J. E. Marion. 1966. Factors affecting oil content and oil composition of corn (Zea mays L.) grain. Crop Sci. 6:41-42.

Jenkins, T. 2011. Managing the rumen environment to control milk fat depression. Pages 31-37 in Proc. Penn State Dairy Nutrition Workshop, Grantville, PA.

Khan, N., J. Cone, V. Fievez, and W. Hendriks. 2012. Causes of variation in fatty acid content and composition in grass and maize silages. Anim. Feed Sci. Technol. 174:36-45.

Klopfenstein, T., G. Erickson, and L. Berger. 2013. Maize is a critically important source of food, feed, energy and forage in the USA. Field Crops Res. 153:5-11.

Martin, R. F. 2000. General deming regression for estimating systematic bias and its confidence interval in method-comparison studies. Clin. Chem. 46:100-104.

Ömer, E. C., K. Fatih, E. Neslihan, K. İsmail, and B. M. Burak. 2016. Analysis of fatty acids in kernel, flour, and oil samples of maize by NIR spectroscopy using conventional regression methods. Cereal Chem. 93:487-492.

Ömer, E. C., F. Kahriman, and M. K. Gül. 2011. Discrimination of maize inbreds for kernel quality traits and fatty acid composition by a multivariate technique. Acta Sci. Agron. 33:613-620.

Pamin, K., W. Compton, C. Walker, and D. Alexander. 1986. Genetic variation and selection response for oil composition in corn. Crop Sci. 26:279-282.

Rico, D. E., and K. J. Harvatine. 2013. Induction of and recovery from milk fat depression occurs progressively in dairy cows switched between diets that differ in fiber and oil concentration. J. Dairy Sci. 96:6621-6630.
Rico, D. E., A. Holloway, and K. Harvatine. 2015. Effect of diet fermentability and unsaturated fatty acid concentration on recovery from diet-induced milk fat depression. J. Dairy Sci. 98:7930-7943.

Rousseeuw, P. J., and A. M. Leroy. 2005. Robust Regression and Outlier Detection. V. 589. John Wiley and Sons, New York, NY.

Stewart, O., G. Raghavan, V. Orsat, and K. Golden. 2003. The effect of drying on unsaturated fatty acids and trypsin inhibitor activity in soybean. Process Biochem. 39:483-489.

Sudar, R., I. Brkić, Z. Jurković, T. Ledenčan, V. Jurković, and D. Šmić. 2012. Fatty acids composition of oil from OS corn hybrids. Page 339 in Proc. 47th Croatian and 7th International Symposium on Agriculture, Opatija, Croatia. University of Zagreb, Faculty of Agriculture, Zagreb, Croatia.

Sukhija, P. S., and D. Palmquist. 1988. Rapid method for determination of total fatty acid content and composition of feedstuffs and feces. J. Agric. Food Chem. 36:1202-1206.

Wassom, J. J., V. Mikkelineni, M. O. Bohn, and T. R. Rocheford. 2008. QTL for fatty acid composition of maize kernel oil in Illinois High Oil $\times$ B73 backcross-derived lines. Crop Sci. 48:69-78.

Weber, E. J. 1978. Corn lipids. Cereal Chem. 55:572-584.

Widstrom, N., and M. Jellum. 1975. Inheritance of kernel fatty acid composition among six maize inbreds. Crop Sci. 15:44-46.

Yang, X., Y. Guo, J. Yan, J. Zhang, T. Song, T. Rocheford, and J. S. Li. 2010. Major and minor QTL and epistasis contribute to fatty acid compositions and oil concentration in high-oil maize. Theor. Appl. Genet. 120:665-678. 